\title{
Review on the Strengthening of Reinforced Concrete Columns by Reinforced Concrete Jacketing
}

\author{
Karim $\mathrm{SH}^{1}$, Karim $\mathrm{FR}^{2 *}$ \\ ${ }^{1}$ MSc Student, Civil Engineering Department, College of Engineering, Sulaimani University, Sulaymaniyah, Iraq \\ ${ }^{2}$ Lecturer, Civil Engineering Department, College of Engineering, Sulaimani University, Sulaymaniyah, Iraq
}

DOI: $10.36348 /$ sjce.2020.v04i01.002

| Received: 15.01.2020 | Accepted: 22.01.2020 | Published: 24.01 .2020

*Corresponding author: Dr. Ferhad Rahim Karim

\section{Abstract}

This paper highlights the review of the behavior and strength of strengthening reinforced concrete columns by reinforced concrete jacketing. Even with the fact that on a massive scale, numerous experimental studies on column strengthening with the assistance of reinforced concrete jacketing are performed after which suggested, however, there may be nonetheless an apparent need for locating and executing new approaches to improve the performance of classical RC jacketing. As in the case of RC structure, columns are subjected to uniform and non-stop loading, which increases with the boom in a number of stories and might cause partly damage or even general failure of the column. To overcome the whole failure of RC columns, instant attention is needed in and the broken part of reinforced concrete repaired by way of reinforced concrete jacketing. This paper additionally focuses on the effect of presenting dowel rebar by way of drilling holes and using concrete jackets made with particular types of concrete. The results show that each use of dowel rebar and distinctive kinds of concrete will increase the bond strength, basic load wearing capability, and primary crack load. Critical cases clarified to avoid such as reinforcing limit and form, type and property of concrete, types of surface preparation, and a recommendation for high temperature.

Keywords: Column, Concrete jacketing, Dowel, Rebar, and Strengthening.

Copyright @ 2020: This is an open-access article distributed under the terms of the Creative Commons Attribution license which permits unrestricted use, distribution, and reproduction in any medium for non-commercial use (NonCommercial, or CC-BY-NC) provided the original author and source are credited.

\section{INTRODUCTION}

Columns are one member of the peak important members in the structure, which transfers the whole loads to the footings. The responsibility of columns inside rising buildings or bridges is significant. Meanwhile, column failure causes extra structural failures and can lead to total building collapse. Strengthening with conventional reinforced concrete jacketing is the old-style and low price technique mostly used to retrofit or repair the damaged concrete structures. It is clear that in classical strengthening, RC jackets became a cost-effective way to provide an increasing strength, total stiffness, and overall enhancement of the structural endurance. And, no hesitation for this reason, although conventional reinforced concrete jacketing demonstrates insufficient deficiencies, it is regularly used either preceding to or even afterward the damage of the reinforced concrete (RC) structural member such as a column.

Moreover, a well-known fact is that the success of the RC jacketing depends upon the better bonding between the broken column and the supplementary jacket and this may be achieved firstly by providing roughness of the contacted face by hammer and chisel or by using a bonding agent like epoxy or by installing shear connectors and dowel rebars [1].

Column concrete jacketing recovers strength, ductility, stiffness, or a combination of previous properties, depending on the type of jacket. The minimum width for cast in place-jacketing is $10 \mathrm{~cm}$, and for shotcrete-jacketing is $4 \mathrm{~cm}$. It recommended that jacketing for all sides of the column should be used. It recommended using the ratio of steel per jacket area between (0.015 to 0.04$)$, and only 3 bars are collected together as a maximum bundle number; in other words, the bundled bars must be below four numbers. The minimum suggested bar diameter for ties is $9.5 \mathrm{~mm} \mathrm{[2]}$.

The need to reeducate a structure may ascend at any time since the start of the building phase up to the end of its service life. Throughout the construction phase, it may occur because of design errors, bad execution of work, and deficiency in concrete 
production. During the service life, it may appear due to an earthquake, an accident, situations involving changes in the structure, functionality, and the development of more demanding code requirements [3].

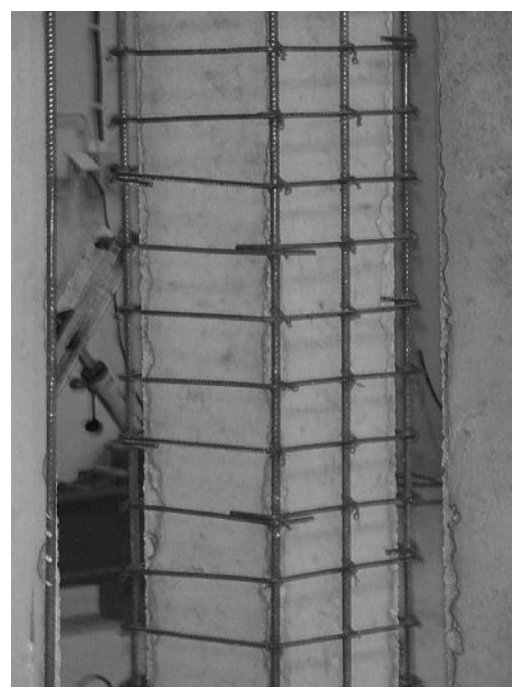

Fig-1: Simple concrete jacketing

\section{Mechanism of action and tests}

In the case of concrete jacketing, a particular amount of the column load is transferred from the existing column to the new concrete jacket due to the bond at the border between existing concrete and the new concrete jacket. The influence of the concrete jacket related to the transport capacity of the strengthened column depends on greatly the quality of connection at the crossing point between existing and new concrete. In the case of thin jackets where the formation of $135^{\circ}$ hooks at the ends of the ties is obstructed by the existing column, an important development in the structural properties of the column can be achieved by welding of the stirrup ends together. Besides, welding the stirrup ends together prevents stirrup opening under loading and supports the longitudinal bars of the jacket to avoid buckling, resulting in better load capacity. Therefore, as far as allout load capacity is concerned, the disadvantage of using a poured concrete jacket instead of a shotcrete jacket can be balanced by welding the stirrup ends together.

There are several testing methods for estimating bond-strength, which is possible to divide into several classes.

The first class of tests, evaluates the bond strength, whereas the bond area is under tensile stress. Pull off, bending, direct tension, and splitting tests are the main types referred to this category, as shown in Fig-2 (a). For the splitting test, also known as the Brazilian test, a concrete prism with circular or square shape may be used and loaded in plumb compression along its length, while located on its side, generating horizontal splitting tensile stresses.
The second class of tests measures the bonding strength while the bonded area subjected to shear stresses. These are named the direct shear approaches, and they comprise several layouts: L-shaped, bi-surface shear, and mono-surface shear tests are among this category, as shown in Fig-2 (b)

The third class of tests measures bonding strength while the bonded area is under a formal of combined compression stresses and shear. Slant shear test method ordered under this class for cylindrical or square prism specimens prepared of two alike halves and bonded together at an inclined surface as shown in Fig-2 (c).

The samples tested under axial compression that produces compression and shear stresses in the contacted area. Generally, the bond-strength is significantly dependent on the type and test method. The resulted strength values obtained from some tests were more up to eight times than those obtained from other tests. Therefore, it is important to select the type of bonding test, which thoroughly represents the real state of stress that the structure subjected to [4].

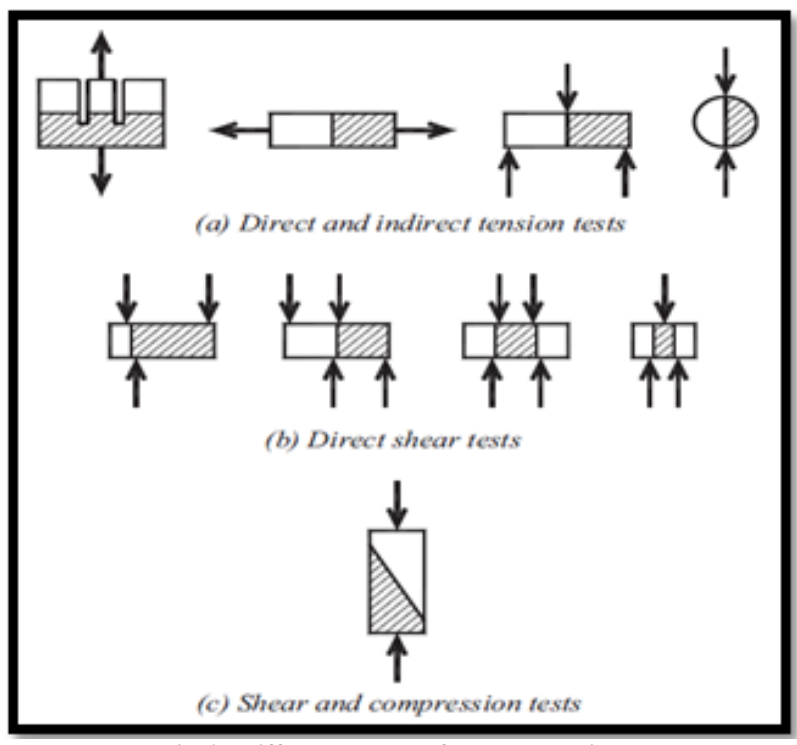

Fig-2: Different classes for bond testing

\section{Concrete jacketing advantages and drawbacks}

The advantages of concrete jacketing in the background of structure in India are as summarized below [5]:

- Concrete jacketing can increase both the flexural and shear abilities of a column.

- Providing compatibility-deformation between old and new concrete, and the durability is better as compared to a new one, because the jacket and column have the same basic materials.

- Availability of employees skilled in concrete building.

- Analysis of treated sections follows the principles of analysis of RC sections. 
It is clear that there are certain drawbacks of concrete jacketing depending on the structure and its use:

- Significant increase in the size of member and reduction in floor space

- Anchoring of bars for flexural strength includes drilling of holes in the slabs and footings, that may produce micro-cracks

- Workability of concrete for the jacketing is more than normal concrete, and then it needed highquality formwork

- Possibility of trouble to the users of the building.

\section{OBJECTIVES OF THIS STUDY}

This study aims to

- Review one of the most typically used strengthening methods for the jacketing of $\mathrm{RC}$ columns.

- To help engineers to choose the most appropriate for strengthening.

- Concrete jacketing procedure

\section{Surface preparation}

Jacketing highly accurate procedure that needed skill and attention to all steps of the work; otherwise, the result may not be as which planned. The concrete jacketing process is summarized below and supported by literature to clarify important points that must be considered during concrete jacketing of columns to provide maximum efficiency and performance.

\section{Surface roughening}

The surface must prepare that maximum bonding achieved between columns and jacketing. Several methods used for this purpose, as summarized below:

All available articles focused on surface preparation as a first and high importance step in concrete jacketing. To obtain an excellent bond between the column and jacket, surface roughening is the best way to increase the bond and support the resulting element to behave monolithically. Also, bonding agents and connectors used to improve the strength of the component. One necessary unanimous inference is the pneumatic hammering source microcracking of the column. This method is usually used to surge the interface roughness but should avoid since it is shown that the mechanical action of the hammering declines the joint [6].

Ju'lio et al. [3] studied the effect of the border between concrete layers of different ages on the power of the joint. The authors performed Slant shear tests and pull-off tests on specimens with the bonding area left as its natural state, prepared by sandblasting, equipped by electric hammering and treated with iron brushing. The authors state that sandblasting was the most efficient coarsening method of those considered. Depending on the previous articles, the best way to roughening the surface is sandblasting.

Julio et al. [6] studied the conditions assumed, or more conservative ones (bending moment/shear force relation greater than $1 \mathrm{~m}$, there is no need to improve the interface surface roughness or to use any kind of bonding agent.

\section{Surface wetting}

The method of pre-wetting the contacting surface is controversial. Even in codes and strategies paradoxes are found on this subject: the AASHTOAGB-ARTBA Joint Committee mentions that the new concrete cast on a non-wetted concrete surface except on hot, dry summer days. The Canadian Standards Association recommends saturating the old concrete surface for at least $24 \mathrm{~h}$ before the concrete jacketing layer is cast [8].

According to Emmons [8], the percent moisture content of the existed column has an effective action on the good-quality bond. It also summarized that an extremely dry column could absorb lots of water from jacketing concrete, causing extreme shrinkage. And high humidity content of the sample can close pores and stop the connection between the column and repairing material. Saturated and surface dry is considered the best solution.

\section{Application of bonding agents}

Due to the wide variety of bonding agents, every article has different results from others. As reported by Elbakry and Tarabia [9], using of bonding agent instead of other methods, reduces $4 \%$ in the strength given by jacketed sample. A small percent like that may be considered unimportant for this test result. Therefore, it determined from this study that using resin materials does not have a respectable result of the jacketing procedure and its outcome.

\section{Shear connector}

One of the most effective ways to improve shear in the jacketed columns is by adding shear connectors. Steel should drill into the existing column and connected jacket to the column. It improved shear resistance and strengthened the result member. The use of dowels considerably improved bond strength. The bond strength of specimens was, on average 4.61 times the corresponding bond strength of specimens that roughened by hand-chiseling or sandblasting. It can seem that a high level of surface roughening provided leads to extra friction between the jacket and the column [9].

\section{Reinforcing the jacket}

It recommended that jacketing for all sides of the column should be used. The ratio of steel to the jacketed area recommended between "0.015 to 0.04 " and no more than 3 bars bundled together. The 
minimum suggested bar diameter of ties is $9.5 \mathrm{~mm}$ [10]. The stirrups act better if hooked by $135^{\circ}$ or welded together to provide maximum efficiency. Also, no more than three bars should fasten together, as shown in Fig$3[5]$.

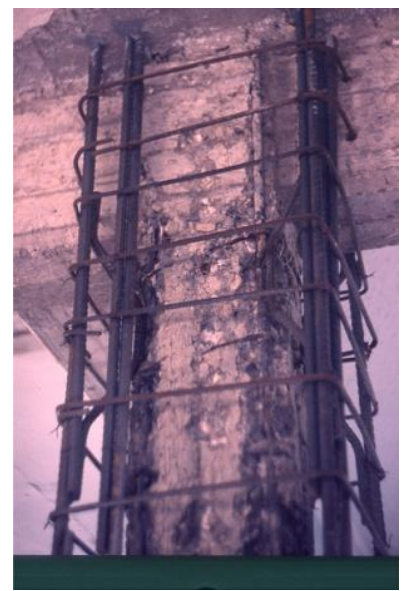

Fig-3: Only two bars bundled together

\section{Pouring concrete}

Usually, the added concrete has a maximum aggregate dimension of about $2 \mathrm{~mm}$ because of the lack of space in the jacket. This preferred due to a reduced thickness of concrete compared with the volume filled by the existed steel reinforcement bars. This property clears the reason why self-compacting concrete (SCC) often used for concrete jacketing. Over, because there is limited space for concrete in steel-reinforced concrete jacketing, it is preferred to use high-strength concrete (HSC) instead of regular concrete (NC). The HSC usually prepared by adding supplementary materials like silica fume (SF). That tends to increase the durability property of HSC, which named highdurability concretes (HDC) and also called highperformance concretes (HPC). Finally, regarding that the concrete of the strengthened column is generally so earlier in age than the jacket concrete, that means all elastic shrinkage complete, it summarized that a nonshrinkage concrete is a perfect choice for $\mathrm{RC}$ jacketing.

Julio et al. [3] concerned with the influence of jacket concrete mix on the behavior of the interface bond property between the jacket and the jacketed column. The authors investigate that better strength of the jacket provides better bonding between the column and the jacket. If high strength concrete or highperformance concrete used, the mode of failure is changing from interface rupture to monolithic rupture.

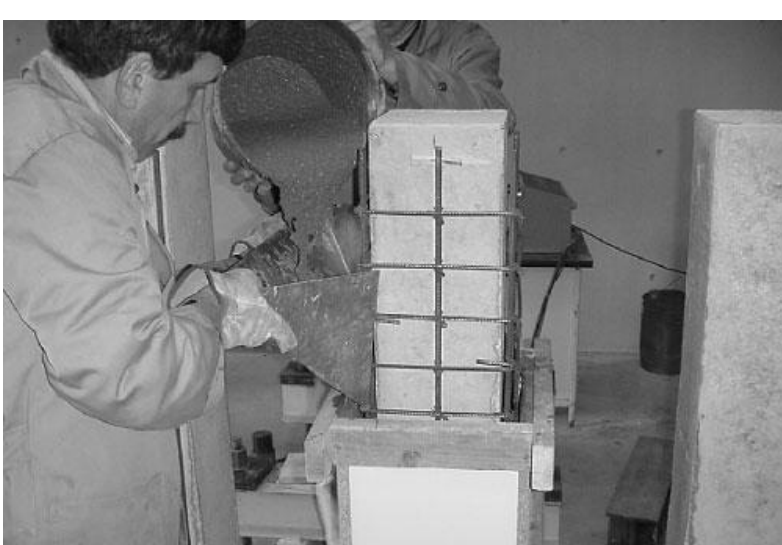

Fig-4: Casting concrete jacket

\section{Literature review on concrete jacketing}

Allam [10], in an experimental study, tries to investigate the properties and behavior of the jacketed columns and the effect of height of the jacket while the original columns were under loading. Six parameters affecting the behavior of strengthening RC columns were studied; jacket thickness, the stress level in the original column, concrete strength of the original column, stirrups of the jacket, shear connectors, and jacket height, respectively. The tested specimens divided into six groups; each group concerned with one of the mentioned six parameters. The following points concluded:

- As the preloading stress in the original column increases the ultimate load of the jacketed column decreases by different percent as $(19 \%, 31 \%$, and $42 \%$ ) for the method of preloading by the working load, 0.5 of the failure load, and 0.8 of the failure load respectively.

- Vertical strains in the jacket decrease as the stress level increases in the original column, which means that jacket efficiency decreases as the stress level increases.

- The lateral tensile strains at the top of the jacket increases as the stress level in the original column increases after the first crack load.

- In the case of the preloaded columns, the vertical strain at the top of the jacket is less than in the case of the total release of load. While for preloaded columns, the vertical strain in the original columns is more than that in the case of the complete release of load at the ultimate load. The Calculation of the strength of the jacket as a RC column overestimates the strength. The overestimation increases in the case of preloaded columns over the cases of the total release of load.

- In the case of loading the original column and the jacket for the preloaded columns, the ultimate load increased by 1.81 times the ultimate load for loading the original column only.

- In the case of the total release of load, the ultimate load increased by 2.05 times the ultimate load for loading the original column only. 
Meda et al. [11] concerned with the strengthening possibility of existing reinforced concrete columns with a method regards to using an ultra-high performance fiber reinforced concrete (UHPFRC) jacket having $170 \mathrm{MPa}$ compressive strength. The geometry of unjacketed, UHPFRC jacketed, and traditional jacketed RC columns are ordered in Figure 2-5 from left to right, respectively.

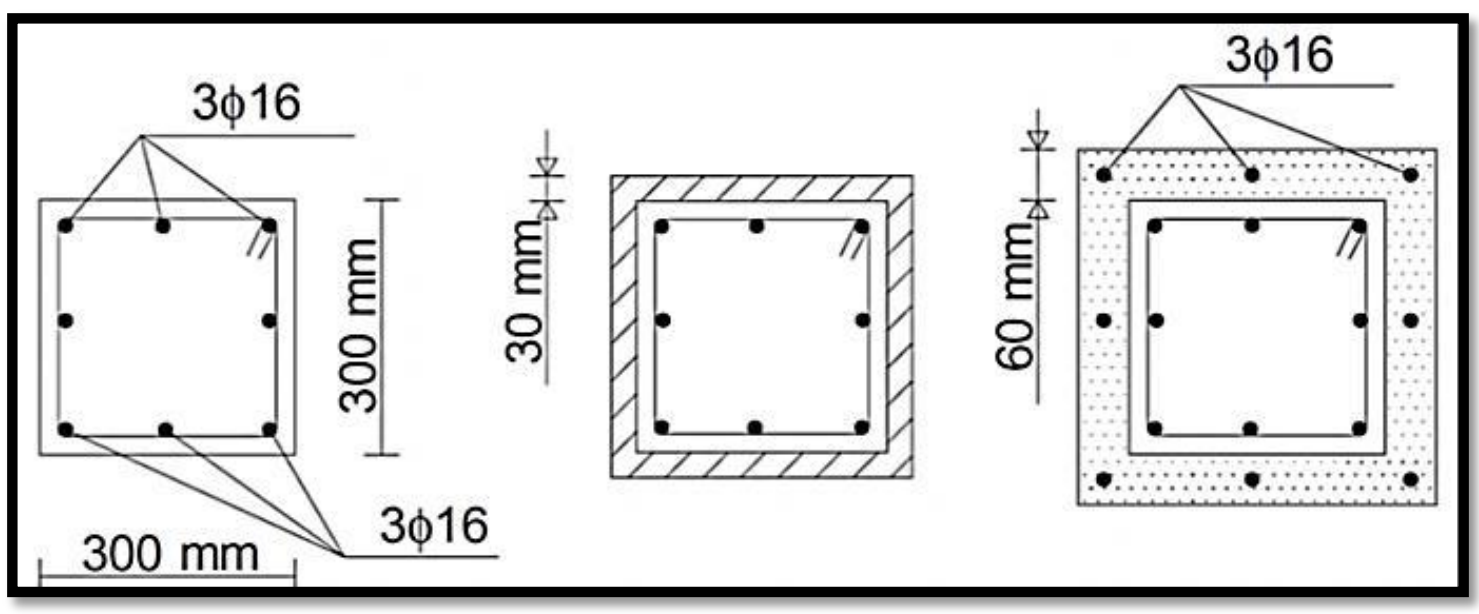

Fig-5: Geometry of un-jacketed, UHPFRC jacketed and traditional jacketed sections from left to right respectively

Both axial load (N) and bending moment (M) were analyzed by analytical drawing interaction envelopes, as seen in Figure 2-6. The obtained results compared with the response of columns strengthened with the traditional jacket, and concluded the following: 1) The use of the UHPFRC jacket for strengthening existing RC columns has shown that a $30 \mathrm{~mm}$ thick jacket allows a significant increase of the bearing capacity both under flexure and axial force.

2) The maximum axial force of strengthening columns equal to $7800 \mathrm{KN}$, which is four times higher than the un-jacketed one.

3) The increase of the pure bending moment is more than $100 \%$, with a maximum value of about 140 KN.m.
4) The UHPFRC jacket also led to an increase of the maximum tensile force that equals to approximately $1000 \mathrm{KN}$ and is more than double of the un-jacketed section.

5) The proposed technique compared to the traditional $\mathrm{RC}$ jacket that requires a higher thickness of the jacket. The UHPFRC jacketing resulted in significant efficiency, particularly of the axial force strengthening. 6) This solution involves a jacket with minimal thickness. Due to the excellent surface quality that can obtain from the UHPFRC material, the jacket can substitute the plaster layer with no significant change in the column size.

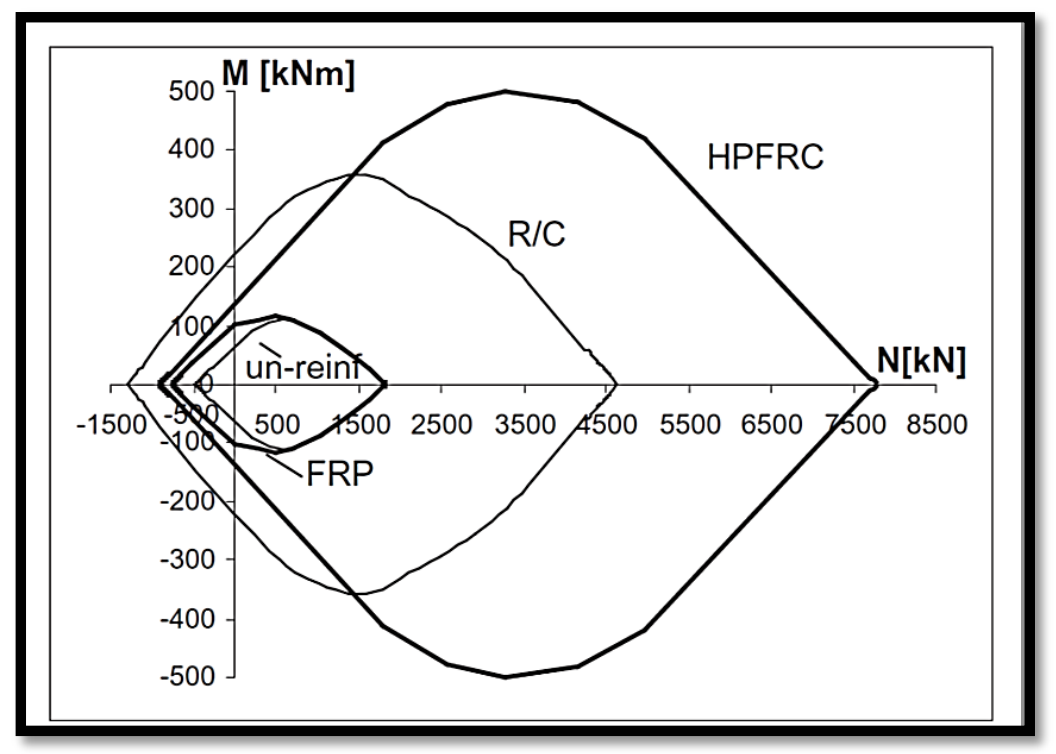

Fig-6: M-N case for famous three different analyzed strengthening systems

CAN [12] has found in his research that the reinforced concrete columns were repaired or strengthened by introducing a new reinforced concrete layer surrounding the existing column as jacketing. 
Although the four-sided jacket is the most popular type sometimes, partial jacketing on two or three sides is inevitable due to space limitations, edge, and corner columns of buildings surrounded by close neighbors. The four and three-sided jacketed columns experimentally investigated under uniaxial loading, and the following results reported:

\section{Columns Jacketed on four faces}

- The jacketing for strengthening resulted in a column capacity of $92 \%$ of the reference (monolithic) specimens.

- There is no reduction in stiffness and ductility; only the axial load capacity is reduced by $8 \%$.

- The jacketing for rehabilitation (repairing) has resulted in a column capacity of $88 \%$ of the reference (monolithic) specimens.

\section{Columns Jacketed on three faces}

- The jacketing for strengthening and rehabilitation (repairing) resulted in a column capacity of $90 \%$ and $82 \%$, respectively, of the reference (monolithic) specimens.

- Column stiffness has increased by $40 \%$ in repairing specimens and $51 \%$ in rehabilitation (monolithic) specimens.

- The strengthened column has dissipated $14 \%$ less energy, and the repaired column $23 \%$ less energy as compared to the monolithic column. Jacketing on all four faces is more efficient from the strength and ductility points of view as compared to jacketing on three faces only.

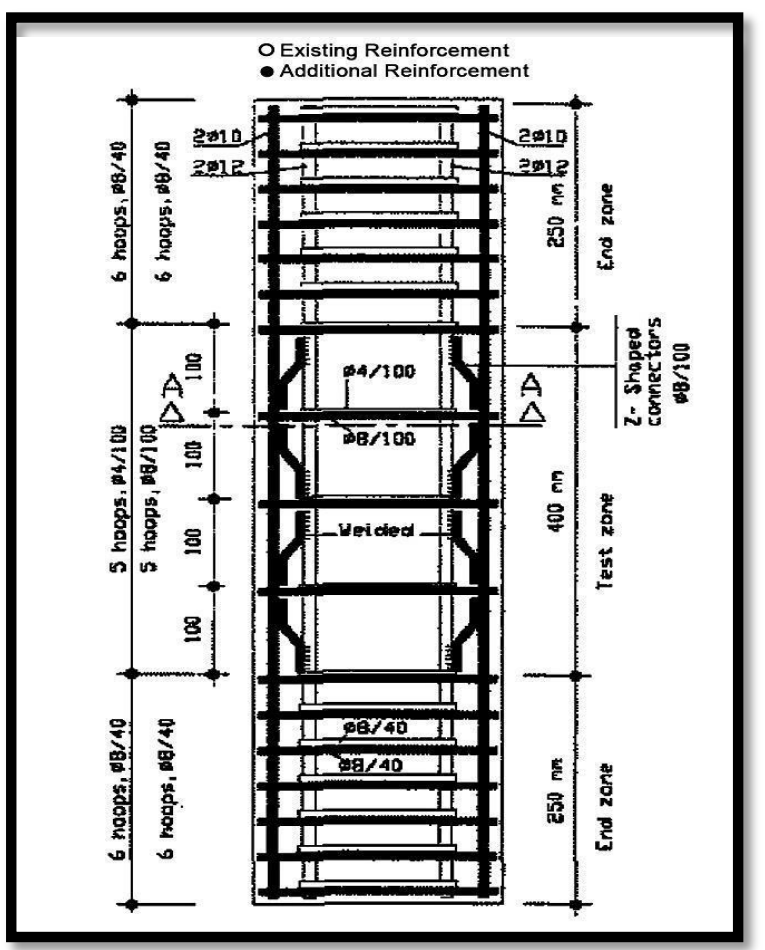

Fig-7: Side view reinforcement of the four sides jacketed columns

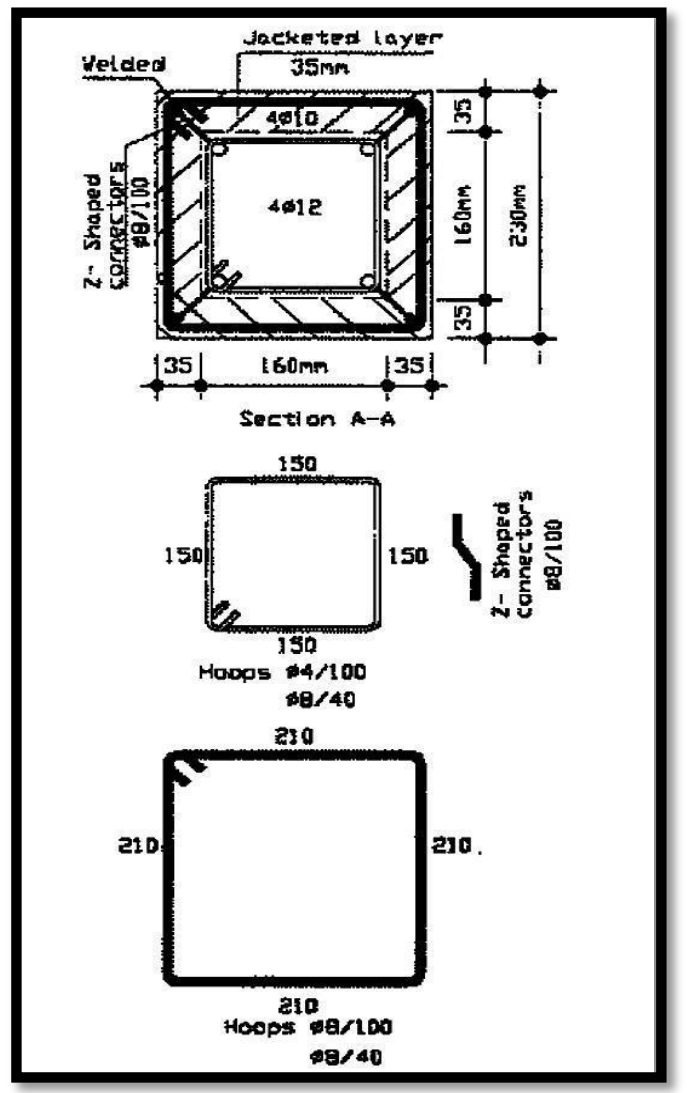

Fig-8: Top view detail reinforcement of the four sides jacketed columns

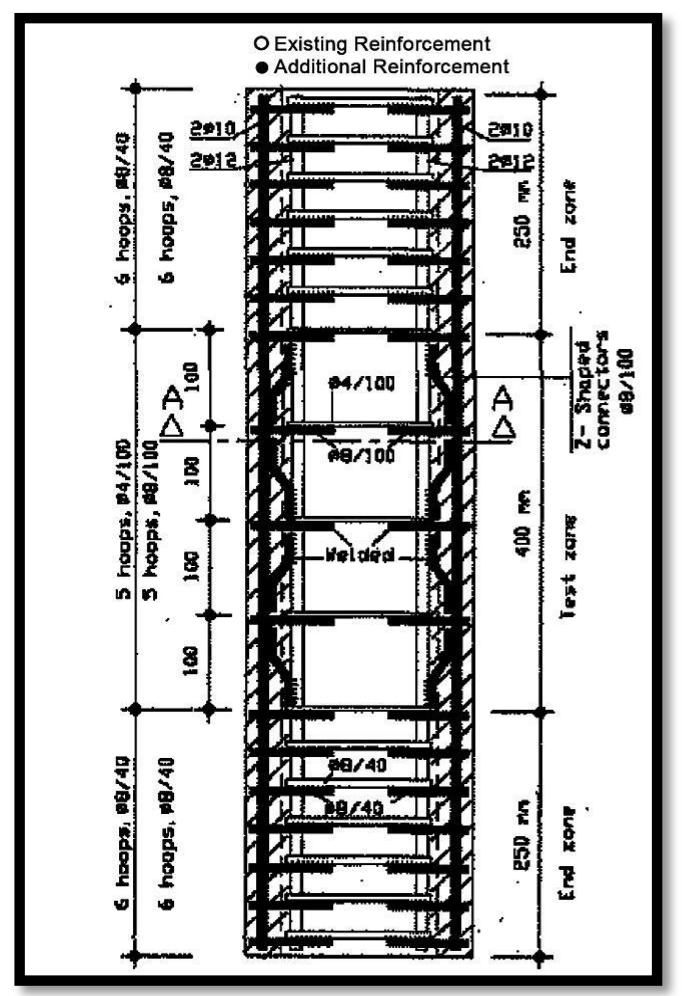

Fig-9: Side view reinforcement of the three sides jacketed columns. 


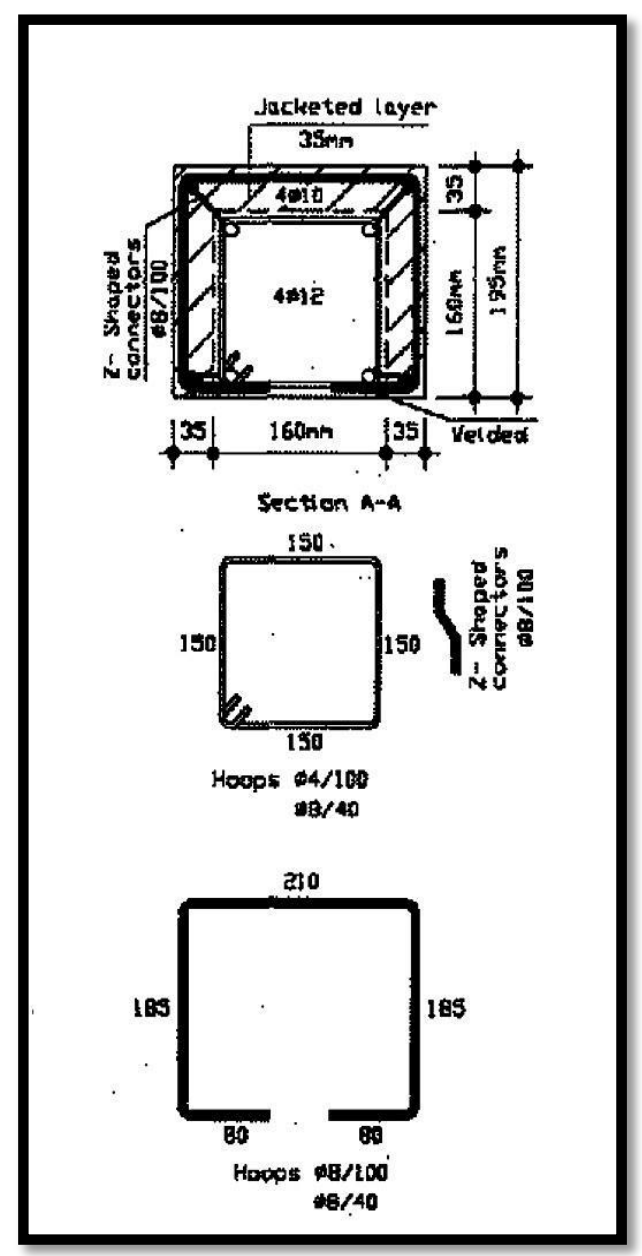

Fig-10: Top view detail reinforcement of the three sides jacketed columns

Mourad et al. [13] has investigated a sequence of 10 small scale square RC columns, put under axial load using preloaded method using various divisions $(0 \%, 60 \%, 80 \%$, and $100 \%)$ of its ultimate load and repaired using high strength ferro-cement for jacketing supported by two layers of steel reinforcement for the high strength mortar and after that tested again up to failure. The overall response of the specimens investigated in terms of load-carrying capacity, axial, and lateral displacement. Fig-11 superimposes the axial and lateral displacement with load-carrying capacity for control columns (SC-2), jacketed columns (SJ-0-2), strengthened preloaded columns (SJ-60-1 and SJ-80-1) and strengthened failed column (SJ-100-1). The study concluded the following points:

- The test results indicated that jacketing reinforced concrete square columns with high strength ferrocement provided about $33 \%$ and $26 \%$ increase in axial load capacity and axial stiffness, respectively, compared to the control columns.

- The test results also indicated that repairing similar reinforced concrete columns (after preloading them to fail) with the same ferro-cement jacket almost restored their original load capacity and stiffness. Furthermore, the repaired columns failed in a ductile manner compared to the brittle failure exhibited by the control columns.

Abdelrahman [14] studied the jackets surrounding the full perimeter of the original columns, which generally used for repair of the interior columns. The level of stress in the column before the repair is assumed to be relatively low to extend that the preloading of the original column does not affect the overall behavior significantly. He also studied the load application on an only sectional area of the original column. It found that the load transfer from the orignal column to the jacket over a distance about 2 to 3 times the breadth of the original column. The ultimate load of this strengthened column was less than the increase in the cross-sectional area.

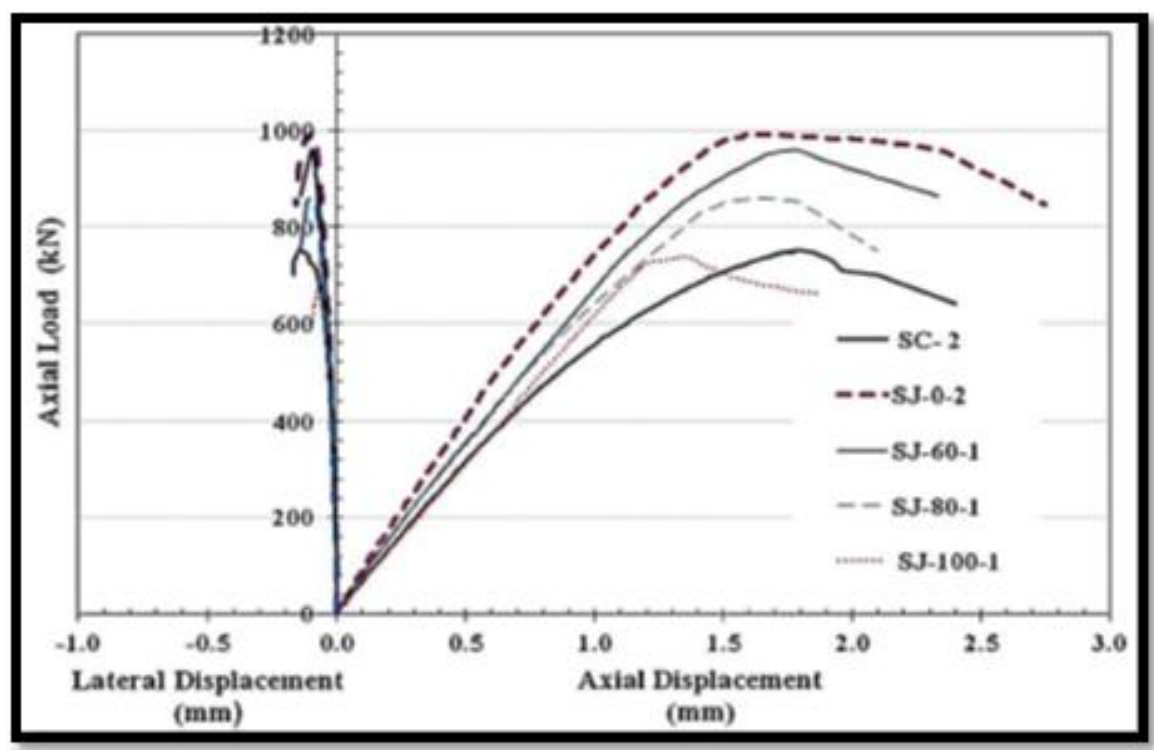

Fig-11: Load-displacement relationships for tested specimens 
Ersoy et al. [15] researched the repair and strengthening of columns by jacketing. The columns tested under uniaxial load, four basic columns are having identical dimensions and reinforcement tested under monotonic axial loading. After the test, the basic columns were jacketed and retested. The intervention was called either a repair or strengthening jacket, depending on the basic specimens that had been loaded into a damaged level. Two of the samples jacketed after unloading the basic column, while the other two jacketed under loading (the load is still in practice), and both cases investigated. The original concrete columns have a cross-section of $13 \times 13 \mathrm{~cm}, 65 \mathrm{~cm}$ in length, $4 \varnothing 10$ main steel reinforcement, and $25 \varnothing 4 / \mathrm{m}$ stirrups. While the jacketed columns of $18 \times 18 \mathrm{~cm}, 65 \mathrm{~cm}$ in length, $4 \varnothing 10$ jacket reinforcement, and $25 \varnothing 4 / \mathrm{m}$ jacket stirrups. Fig-12 shows the cross-section of the specimens.

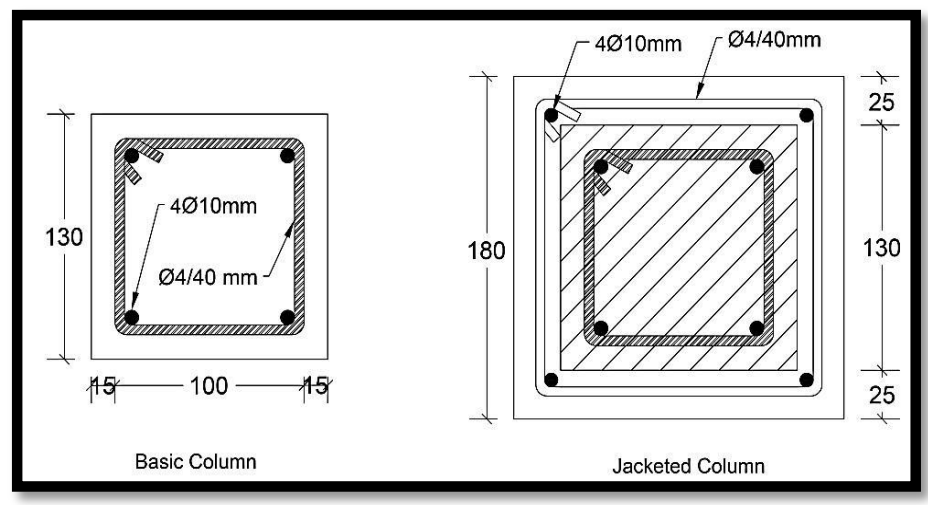

Fig-12: Cross-section of specimens

In addition to the four jacketed columns, a reference specimen (M) with dimensions and reinforcement identical to those of the jacketed columns tested, in this specimen, the primary column, and the jacket cast monolithically. Axial load versus axial strain curves for the jacketed and monolithic samples given in Fig-13. And the following points were concluded:

- Strengthening jackets were quite useful. The specimen in which jacketing was made under load (US) behaved almost as well as the one in which jacketing was made after unloading (LS). Samples with strengthening jackets reached from $90 \%$ to $95 \%$ of the capacity of the reference specimen.

- The sample with the repair jacket made after unloading (UR) behaved well and reached $80 \%$ of the capacity of the reference specimen.

- $\quad$ The sample with the repair jacket made under load (LR) did not behave well and failed when it reached $80 \%$ of the reference specimen capacity.

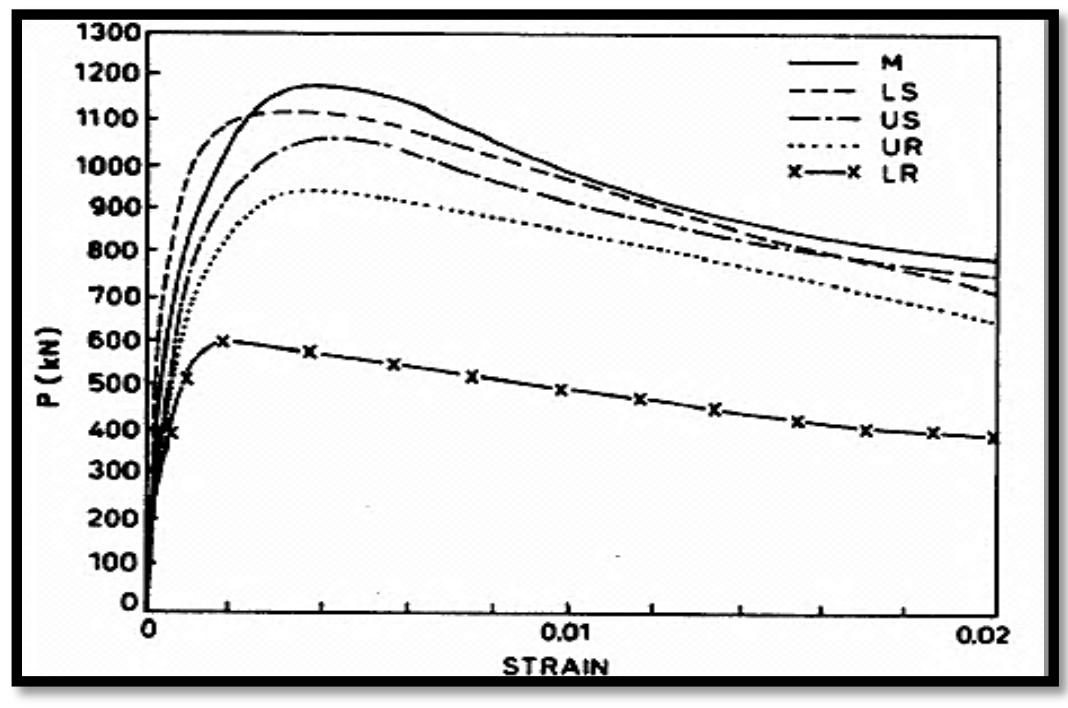

Fig-13: Load-strain curves of column specimens

Vandoros and Dritsos [16] have presented an investigation of the effectiveness of using alternative techniques to place concrete jackets to strengthen RC columns. See Fig-14 for detailed geometry. Three different jacket construction procedures used. Besides, for comparative purposes, the results from two specimens strengthened using Carbon FRPs have been presented. 


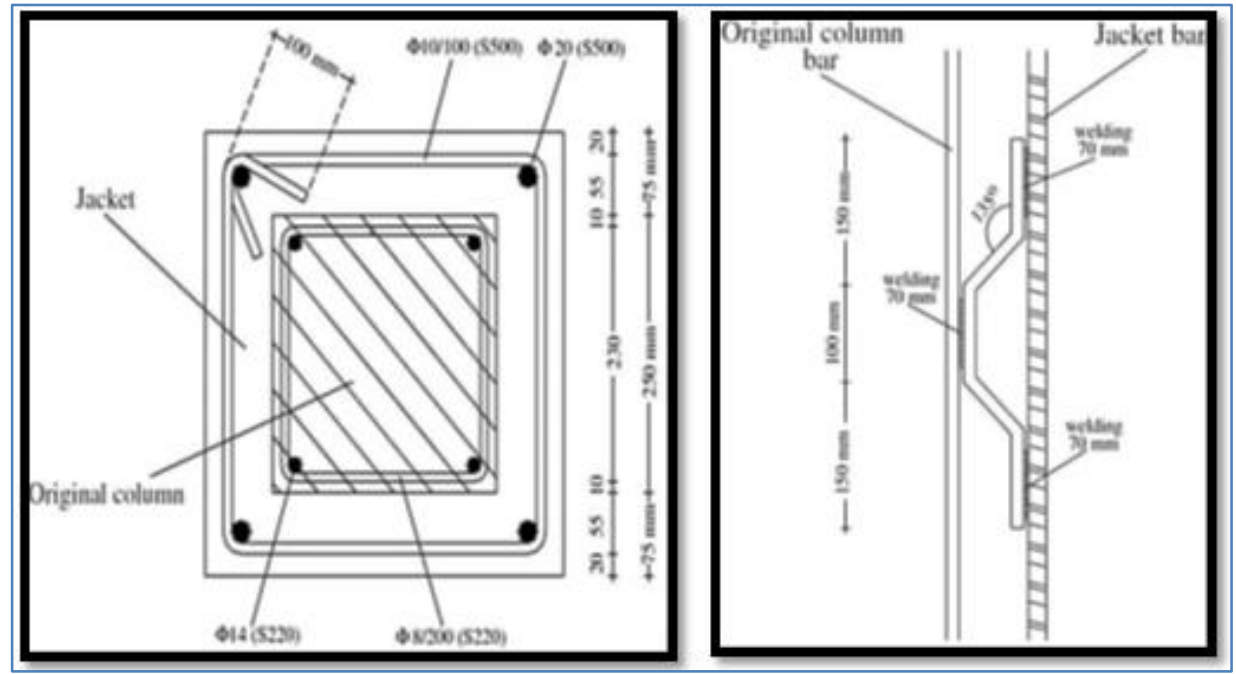

Fig-14: Geometry of cross-section and bent down steel connector

On the other hand, when concerned with load capacity and initial stiffness, the connection effect is not significant, summarizing that the stirrup anchorage at the ends can be guaranteed using a welding tie ends together. It also pointed out that, in general, and the stiffness and even the strength of the jacketed samples were lower compared to the individual monolithic element.

But, the energy degeneracy rate became higher than that of the monolithic specimen if bent down steel connectors used to provide the connection between the column reinforcement bars and the jacket reinforcement bars.

Therefore, if energy degeneracy capacity is concerned, it is proven that using this method and combining with a shotcrete jacket may be the most effective condition. In addition to this, by welding, the stirrup ends together stirrup-opening, and longitudinal bar buckling prevented, while better maximum load capacity provided.

Therefore, as far as maximum load capacity is concerned, the disadvantage of using a poured concrete jacket instead of a shotcrete jacket can be offset by welding the stirrup ends together. The failure mechanism and the observed crack patterns, influenced by the strengthening method.

The separation of the jacket from the original column was evident in the case where there was no treatment, or other connection means performed at the contact interface between the column and the jacket, See Fig-15 for the plotted results. The study demonstrated that placing concrete jackets around columns increases the strength and the stiffness while placing Carbon fiber reinforced polymers significantly increases the ductility.

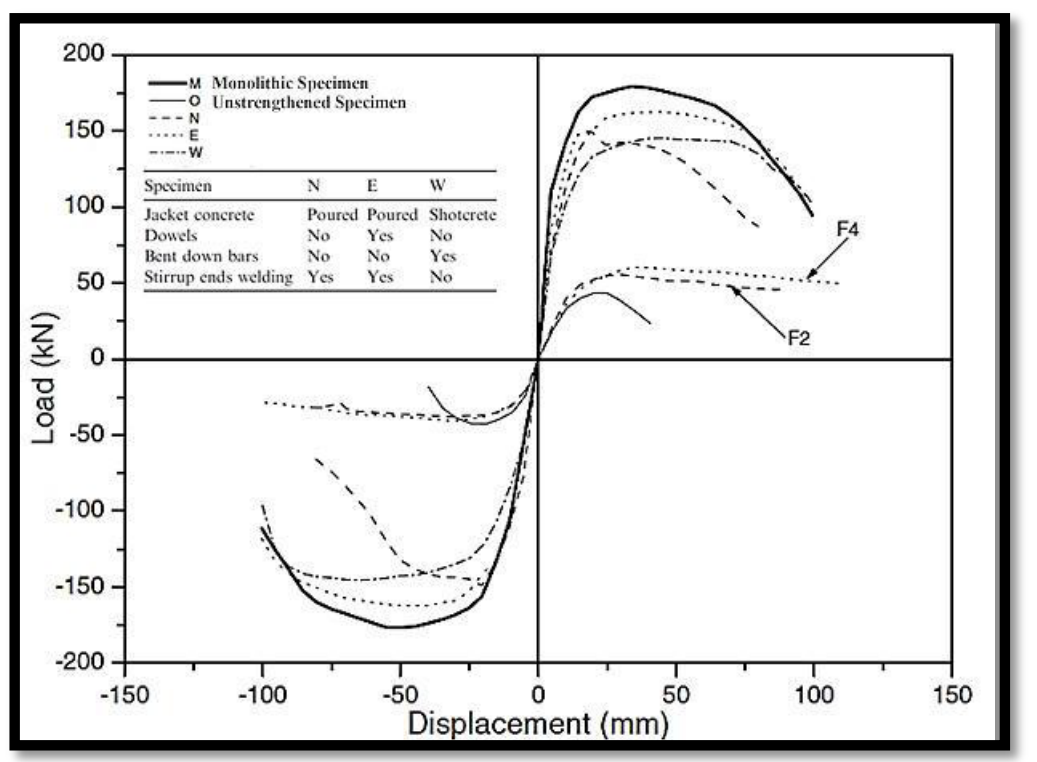

Fig-15: Load against displacement envelopes for all specimens 
Ramirez [17] performed an experimental study to compare the characteristics and effectiveness of ten RC column repair methods. The repair performed to counterbalance a significant or total loss of carrying capacity. The techniques presented are divided into two groups. The first deals with the strengthening of the entire column height, while the second focuses on the problem of damage and loss of strength in a localized section. Different kinds used on standard and polymeric concrete jackets, steel profiles, bonded, welded or bolted plate jackets, and encasements.

Considering the first six methods that extend along with the entire column height, the most exciting methods, in terms of efficiency and cost, appear to be the simple concrete jacket and the steel angle method. The simple concrete jacket is easy to construct, and the transmission of the load is direct. It is advisable to make a unique bar hoop reinforcement at the two extremes of the jacket, close to the surfaces of the slab, to improve the performance. This is necessary when the size of the original upper column is smaller than that of the strengthened one.

Ju'lio et al. [3] studied the structural rehabilitation of columns with reinforced concrete jacketing. They concluded that the RC jacketing strengthening method, unlike other techniques, leads to a uniformly distributed increase in strength and stiffness of columns. Further, the durability of the original column is also improved, in contrast to the corrosion and fire protection needs of other techniques where steel is exposed or where epoxy resins used. Moreover, removing the concrete from the deteriorated zone by hand chipping, jack-hammering, electric hammering, or any other method that causes micro-cracking of the substrate should be followed by sandblasting or water demolition techniques.

Kaliyaperumal and Sengupta [18] investigate the effect of concrete jacketing on the flexural strength and performance of columns, and it was concluded that the self-compacting concrete was found to be suitable for use in the concrete jacket and the retrofitted specimens did not show any visible delamination between the existing concrete and the concrete in the jacket. Moreover, the roughening of the surface of the existing concrete with a motorized wire brush found to be satisfactory for the type of tests conducted. Further, this study can extend to the exterior of the corner columns by testing the corresponding sub assemblage specimens.

Nasersaeed [19] stated that using the concrete jacket is an effective method in increasing strength and stiffness in a structural frame and further concluded that $\mathrm{RC}$ jacketing technique is cheaper than other retrofitting techniques because of the availability of materials and no requirement of highly trained labor. Also, the congested arrangement of reinforcement limits the volume of extra concrete and buckling of longitudinal bars in the repaired concrete column.

Dadasaheb et al. [20] studied the structural behavior of RCC building and stated that it is better to implement classical reinforced concrete jacketing due to its feasibility and ease for execution. Further, strengthening of building considered in this study is an attempt to increase life and to sustain unwanted disturbances like earthquakes, floods, etc. It recommended retrofitting the old RCC structures with this suitable type of jacketing at the proper time such that it may prove economical and safe for the future.

S. H. Sayed [21] concerned with the influence of column repairing after exposure to elevated temperature depending on using different concrete jacket types. Also, the impact of shear connectors on the bond quality between the sample contact surface with the RC jacket is studied. Summarized that, at elevated temperature, the ultimate load of concrete columns reduced, while using shear connectors improves this case slightly. Further, it proved that for those columns that exposure to high temperatures, SCC jacket is most dependable, but the use of recycled concrete should be avoided for RC column repairing.

Elbakry and Tarabia [9] studied the effects of surface preparation, the contributions of dowels, and concrete jacket transverse reinforcement on the overall bond strength between new concrete jackets and old concrete. Thus, it concluded that increasing the surface roughness of the substrate concrete by hand-chiseling is considerably more effective than grinding, and the use of steel dowels to connect the new jacket concrete to the old concrete significantly improved the overall bond strength due to the developed shear friction.

\section{CONCLUSION}

The following conclusions can be drawn from this study, which is reviewed on the concrete column strengthening using reinforced concrete jacketing:

1. For surface preparation sandblasting method has the best result science, it provides monolithically behavior for a resulted member during failure. In contrast, the pre-wetting way may lead to disjointing in the contact area because of that the pores filled with water.

2. The ratio of steel in RC jacketing is 0.025-0.04 and recommended that no more than three steel bars bundled together; the ties must be hooked be $135^{\circ}$ or welded at the ends.

3. Concrete of jacket recommended to be workable, self-compacted, non-shrinkable, and low maximum size aggregate due to lack of spacing.

4. Using UHPFRC for jacketing is very effective; casting $3 \mathrm{~cm}$ thickness jacket increases $100 \%$ strength of the column compared with $6 \mathrm{~cm} \mathrm{RC}$ jacket. 
5. Four-side jacketing is the best method to increase, strengthening if space permits.

6. Ferrocement jacketing provides failure in a ductile manner compared to the brittle failure of the nonjacketed sample.

7. Welded bars avoid columns from tie-opening and support longitudinal bars from buckling.

8. Hand-chipping, jack-hammering and electrical drilling causes micro-cracks and should avoid as possible.

9. In case of high temperature, shear connectors must be used with SCC, while recycled concrete does not recommend.

\section{REFERENCES}

1. Sheikh, T. R., Khan, M. K., \& Izhar, T. (2017). A review on Strengthening of RCC square columns with Reinforced Concrete Jacketing.

2. Teran, A., \& Ruiz, J. (1992). Reinforced concrete jacketing of existing structures. In Earthquake Engineering, 10th World Conference, Balkema, Rotterdam.

3. Júlio, E. S., Branco, F., \& Silva, V. D. (2003). Structural rehabilitation of columns with reinforced concrete jacketing. Progress in Structural Engineering and Materials, 5(1), 29-37.

4. Julio, E.S., Branco, F., \& Dias da Silva, V. (2001). A influência da interface no comportamento de pilares reforc, ados por encamisamento de beta o armado. Proceedings of the Congresso Construc, a o 2001, IST, Lisbon, 17-19 December 2001: 1: 439-446.

5. Chakrabarti, A., Menon, D., \& Sengupta, A.K. (2008). "Handbook on Seismic Retrofit of Buildings", Narosa Publishing House, New Delhi.

6. Julio, E.S. (2001). A influe^ncia da interface no comportamento de pilares reforc, ados por encamisamento de beta o armado, PhD Thesis, Universidade de Coimbra.

7. Saucier, F., \& Pigeon, M. (1991). Durability of new-to-old concrete bondings. Proceedings of the ACI International Conference on Evaluation and Rehabilitation of Concrete Structures and Innovations in Design, Hong Kong, 1: 689-707.

8. Emmons, P.H. (1994). Concrete Repair and Maintenance. Part 3: Surface Repair, Section 6: Bonding Repair Materials to Existing Concrete. RS Means Company, MA: 154-163.
9. Elbakry, H. M., \& Tarabia, A. M. (2016). Factors affecting bond strength of RC column jackets. Alexandria Engineering Journal,55(1), 57-67.

10. Allam, H. M., (1995). Strengthening of loaded columns by R.C. jackets, $\mathrm{PhD}$ thesis, Cairo University, Faculty of Engineering.

11. Meda, A., Plizzari, G.A., Rinaldi, Z. (2009). Strengthening of RC existing columns with highperformance fiber-reinforced concrete jacket, \| University of Bergamo, Bergamo, Italy.

12. CAN, H. (1995). Partially Jacketed (Two, Three, Four Sides) Reinforced Concrete Column Behavior under Uni-Axial Loading\|, Faculty of Engineering and Architecture, Dept. of Civil Engineering, Ankara, 6(4), 1063-1081.

13. Mourad, S. M., Shannag, M. J. (2012). Repair and Strengthening of Reinforced Concrete Square Columns Using Ferrocement Jackets, ॥ Department of Civil Engineering, College of Engineering, King Saud University, Riyadh, Saudi Arabia.

14. Abdelrahman, A. (1985). Strengthening of columns by concrete jackets, $\| 1$ st Egyptian Structural Engineering Conference, Cairo University, April.

15. Ersoy, U., Tankut, A., \& Suleiman, R. (1993). Behavior of jacketed columns,\| ACI Structural Journal, Title no. 90-S30, 288- 293.

16. Vandoros K.J., \& Dritsos, S. E. (2006). Concrete jacket construction detail effectiveness when strengthening RC columns, \| Construction and Building Materials.

17. Ramirez J. L. (1995). Ten concrete column repair methods, Construction and Building Materials, 10(3): 195-202.

18. Gnanasekaran, K., \& Amlan, K.S. (2009). "Seismic retrofit of columns in buildings for flexure using concrete jacket". ISET Journal of Earthquake Technology, 505, 46, 2.

19. Hamidreza, N. (2011). "Evaluation of Behaviour and Seismic Retrofitting of RC Structures by Concrete Jacket." Asian Journal of Applied Sciences.

20. Bhavar, D., Dhake, P.D., \& Ogale, R.A. (2013). "Retrofitting of Existing RCC Buildings by Method of Jacketing". IJRMEET, 1(5).

21. Sayed, H. Sayed. (2015). "Retrofitting of Concrete Short Columns after Subjecting to Elevated Temperature Using Different Types of Concrete Jackets". World Applied Sciences Journal, 33(5): 790-796. 